\title{
Corrigendum to "A Three-Point Boundary Value Problem with an Integral Condition for a Third-Order Partial Differential Equation"
}

\author{
C. Latrous and A. Memou \\ Laboratoire Equations Differentielles, Département de Mathematiques, Université Mentouri Constantine, 25000 Constantine, Algeria \\ Correspondence should be addressed to C. Latrous; latrouschah@gmail.com
}

Received 17 July 2017; Accepted 3 August 2017; Published 26 November 2017

Copyright (c) 2017 C. Latrous and A. Memou. This is an open access article distributed under the Creative Commons Attribution License, which permits unrestricted use, distribution, and reproduction in any medium, provided the original work is properly cited.

In the article titled "A Three-Point Boundary Value Problem with an Integral Condition for a Third-Order Partial Differential Equation" [1], a previous related article by Denche and Memou should have been discussed [2]. The articles study the same partial differential equation, with different integral boundary conditions. Denche and Memou deal with an integral condition on the whole space domain, whereas Latrous and Memou use the integral condition only on a variable part of the domain. The solution methods applied in each study are different.

\section{References}

[1] C. Latrous and A. Memou, "A three-point boundary value problem with an integral condition for a third-order partial differential equation," Abstract and Applied Analysis, vol. 2005, no. 1, pp. 33-43, 2005.

[2] M. Denche and A. Memou, "Boundary value problem with integral conditions for a linear third-order equation," Journal of Applied Mathematics, vol. 2003, no. 11, pp. 553-567, 2003. 


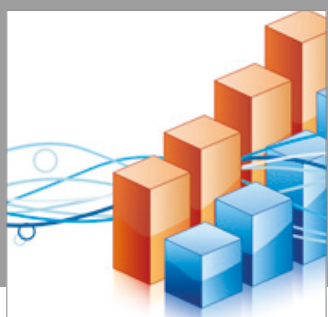

Advances in

Operations Research

vatersals

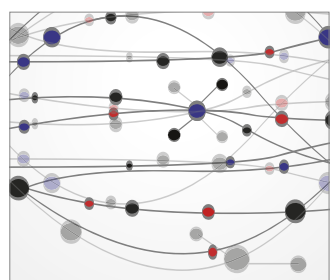

\section{The Scientific} World Journal
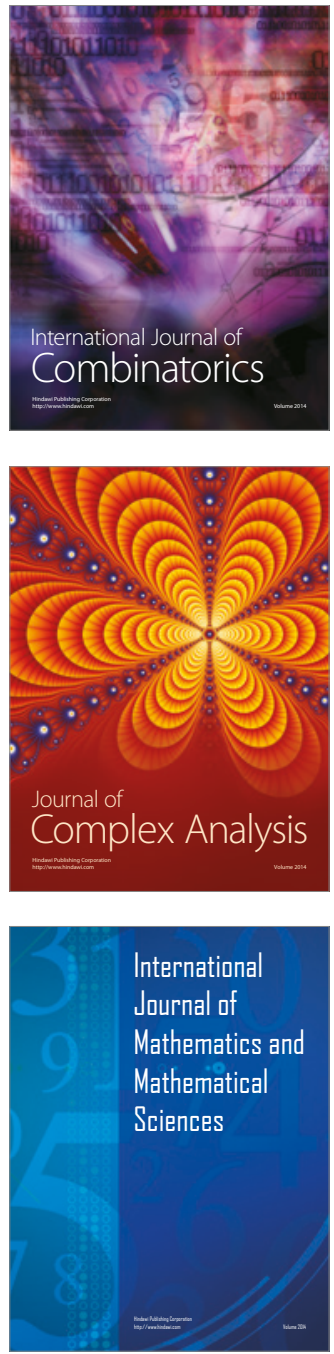
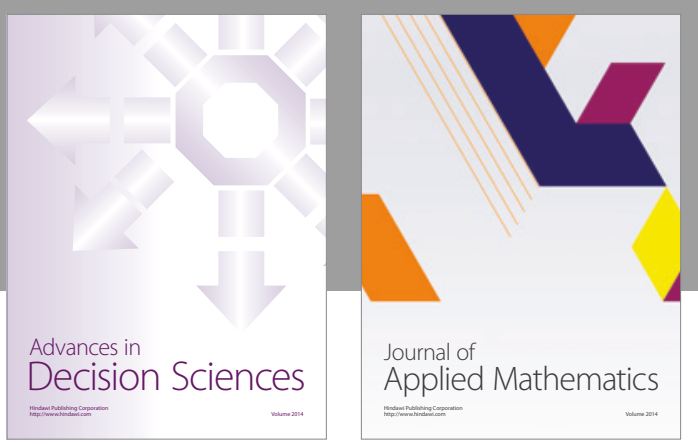

Algebra

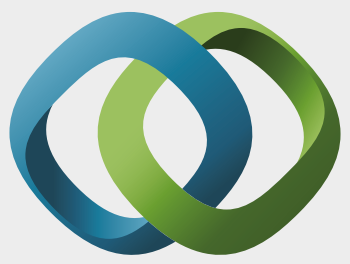

\section{Hindawi}

Submit your manuscripts at

https://www.hindawi.com
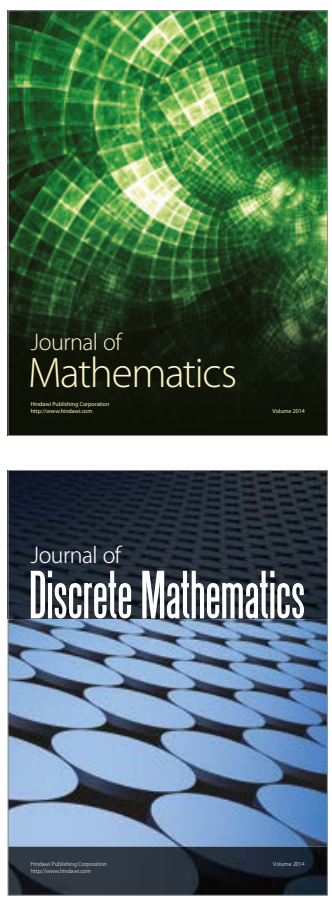

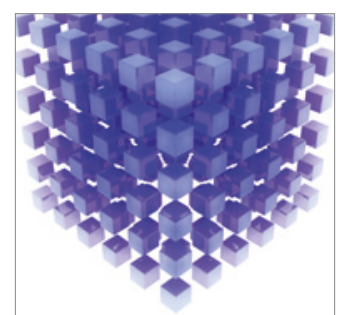

Mathematical Problems in Engineering
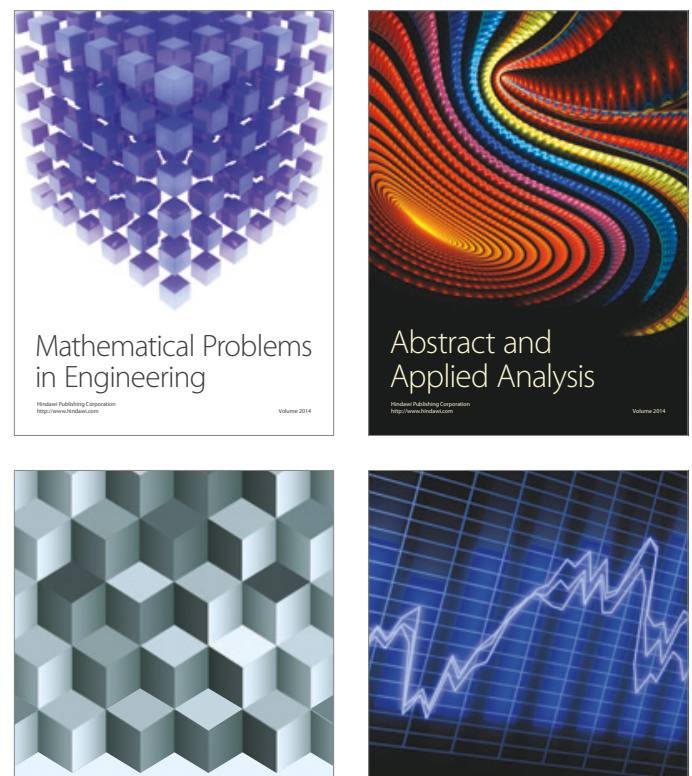

Journal of

Function Spaces

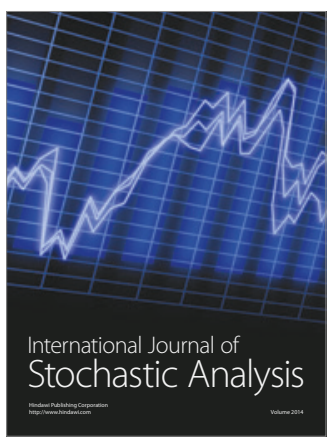

Probability and Statistics
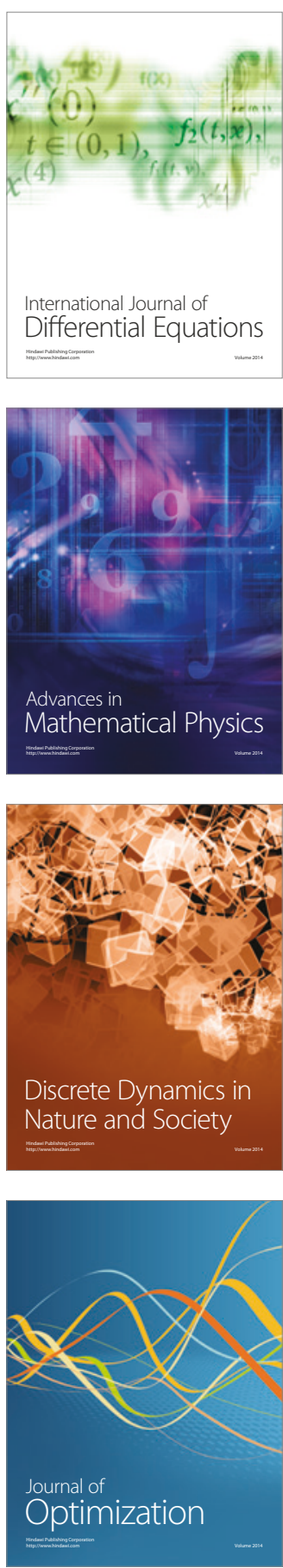